\title{
Information About COVID-19 Testing on College Websites in the New York City Metropolitan Area
}

\author{
Corey H. Basch ${ }^{1}\left[\right.$ D Marianne Sullivan ${ }^{1} \cdot$ Aleksandar Kecojevic $^{1} \cdot$ Nasia Quinones $^{1}$
}

Accepted: 29 January 2021 / Published online: 10 February 2021

(c) The Author(s), under exclusive licence to Springer Science+Business Media, LLC part of Springer Nature 2021

\begin{abstract}
The continuing COVID-19 pandemic significantly impacted the Fall reopening plans among institutions of higher education (IHEs) in the United States (U.S.). While recommendations were made to conduct COVID-19 testing of students and staff, it is unclear as to what extent IHEs were able to engage in testing. IHEs also play a critical role in provision of accurate information related to COVID-19 to students and staff. The purpose of this cross-sectional study was to assess available information on COVID-19 testing on IHEs' websites in the New York City (NYC) metropolitan area. IHEs' websites were screened for the presence of content related to COVID-19 testing. Larger institutions ( $>10,000$ students) were more likely than smaller institutions ( $\leq 5000$ students) to provide information on how to make an appointment for COVID-19 testing $\left(\chi^{2}(2)=8.1, P<0.05\right)$, and information on free testing $\left(\chi^{2}(2)=7.0, P<0.05\right)$. Of 150 IHEs included, $124(82.7 \%)$ IHE's reported testing data to the campus community, with the majority providing this data biweekly (62.9\%). A total of 116 IHEs recorded at least one positive COVID-19 case among their students or staff during the Fall semester. Smaller-sized institutions reported a significantly lower number of cases than medium- $(P<0.001)$ and large-sized $(P=0.003)$ institutions. Additional differences related to testing modalities and provision of information were observed according to schools' state jurisdictions. Although geographically close, IHEs in the NYC metropolitan area did not provide information on COVID-19 testing in a uniform and comprehensive fashion, which may further contribute to public confusion.
\end{abstract}

Keywords COVID-19 $\cdot$ Testing $\cdot$ College students

\section{Introduction}

The outbreak and community transmission of COVID-19 in the United States (U.S.) in March and April of 2020 impacted many, including U.S. institutions of higher education (IHEs). The New York City (NYC) metropolitan area, defined as a geographic area encompassing counties in close proximity to NYC [1], was among the hardest hit areas in the country, forcing IHEs to close campuses, transition to online instruction and send residential students home for the remainder of the Spring 2020 semester [2]. In the late spring and early summer of 2020, as new infections were declining, attention shifted to how to safely re-open IHEs for the fall semester. Given the importance of higher education, ensuring the continuation of research, and the contribution of

Corey H. Basch

baschc@wpunj.edu

1 Department of Public Health, William Paterson University, Wayne, NJ 07470, USA
IHEs to local and state economies, reopening plans became a priority for school administrators. While the majority of IHE students are not at high risk of severe morbidity or mortality due to COVID-19, experts recognized that outbreaks among college students could put faculty and staff at risk, as well as vulnerable members of surrounding communities [3]. Recommendations for IHEs provided by the U.S. Centers for Disease Control and Prevention (CDC) suggest a tiered approach to risk reduction [4]. Among measures aimed at reducing the spread of COVID-19, the CDC recommended testing of "students, faculty, and staff for purposes of surveillance, diagnosis, screening, or in the context of an outbreak," and discussed the likelihood of off-campus transmission. CDC recommendations were meant to supplement local, state or federal rules and regulations for IHEs, and implemented in collaboration between IHE administrators and state and local health officials [4]

New York (NY), New Jersey (NJ), and Connecticut (CT), developed guidance for Fall 2020 IHE reopening, which varied in scope and stringency [5]. Of the three, CT's 
guidelines called for the most comprehensive COVID-19 testing strategies, recommending that residential campuses conduct arrival testing and symptomatic and ongoing surveillance testing. Non-residential campuses were only required to plan for symptomatic testing for students, faculty, and staff [3]. NJ's restart guidance mandated that IHEs establish COVID-19 testing plans, yet the specifics were left to individual institutions [6]. NY's IHEs reopening guidelines listed mandatory and recommended best practices (i.e., arrival and ongoing systems for testing on campus). However, no surveillance testing was required [7]. Yet, it was clear during the summer of 2020 that many IHEs would face barriers implementing comprehensive testing strategies. These included cost, logistics, limited testing supplies, and inadequate laboratory capacity $[8,9]$ These barriers could have been particularly significant for smaller colleges, and colleges under financial strain.

Another aspect of an IHE's testing strategy is its health communication plan about testing (e.g., its importance, the logistics, and the results). Gaining compliance with public health measures like testing on campus is likely to be improved by well thought out health communications regarding transmission dynamics and the importance of testing. This issue is particularly important for college-aged students who, while at lower risk of adverse outcomes of COVID-19, may benefit from messaging about their important role in preventing transmission and protecting others [10]. The CDC recommendations emphasize the importance of "providing information on the process of case investigation and contact tracing to students, faculty, and staff [4]." Although the NY and NJ guidance acknowledged the importance of an IHE's communication plan, none of the three state guidance documents make specific best-practice recommendations for IHEs to follow. In the absence of clear guidelines, it is unknown to what extent the IHEs developed and implemented communication plans to their students and staff regarding testing, including whether adequate and accurate information on COVID-19 surveillance and testing is present on their websites. There is a dearth of published literature related to COVID-19 communications by the IHEs. Therefore, the purpose of this study was to describe information on websites of IHEs in the NYC metropolitan area related to IHE COVID-19 testing plans and results.

\section{Methods}

This cross-sectional study took place over the Fall 2020 semester and included IHEs in the New York City (NYC) metropolitan area. All IHEs in New York (NY), New Jersey (NJ), and Connecticut (CT) were identified using College Navigator, a search tool of The National Center for Education Statistics (NCES), part of the U.S. Department of
Education [11]. The sample was further refined to include only IHEs in the counties defined by the NYC metropolitan area (NYC planning). Inclusion criteria hinged upon the colleges and universities having an operational website. Undergraduate and graduate student enrollment data for each school was identified using the data provided on the institution's website, and when this information was not available, it was garnered from the College Navigator tool. Based on enrollment information, institutions were categorized into small- ( $\leq 5000$ students), medium- (5001-10,000) and large$(>10,000)$ sized institutions. We also noted whether institutions were public or private.

After determining if the Fall 2020 semester classes were held in person in some capacity (i.e., hybrid) or fully online, colleges' and universities' websites were coded for the presence of content related to COVID-19 testing. Content categories included the following: general information on COVID-19, information on reasons for testing, statements on urgency of testing if exposed or symptomatic, information on COVID-19 testing on and/or off campus, information on surveillance testing conducted by individual schools, information on how to make an appointment for COVID-19 testing, whether website included information on free testing, if social media was used to promote testing, and whether colleges reported their testing data to campus community. All content categories were coded dichotomously $(0=$ information absent, $1=$ information present). We also collected information on whether institutions reported testing data to the campus community $(0=$ no, $1=y e s)$, whether they reported positive COVID- 19 cases $(0=$ no, $1=$ yes), the positive case count, and the frequency of the dashboard updates on COVID- 19 cases as obtained ( $0=$ weekly, $1=$ biweekly). Finally, we noted the time (in minutes) spent to navigate college websites looking for COVID-19 information. All data analysis was completed using SPSS 26.0 [12]. The Institutional Review Board at William Paterson University does not review studies devoid of animals or human subjects.

\section{Results}

We identified 150 community colleges and universities in the NYC metropolitan area (Table 1). Slightly over half (50.7\%) of the sample were small colleges with an average enrollment of 1988 students (range 55-4875). Medium size colleges with an average enrollment of 7245 students (range 50279916) accounted for $24.6 \%$, while large colleges with an average enrollment of 18,197 students (range 10,105-63,778) accounted for $24.7 \%$ of the sample. Overall, the majority of institutions were private (58\%), with small colleges more likely to be private, while medium and large schools were more likely to be public institutions $\left(\chi^{2}(2)=31.3, P<0.001\right)$. Only about $10 \%$ of colleges were fully online during the Fall 
Table 1 COVID-19 testing information presented on colleges' websites in New York City (NYC) metropolitan area stratified by the college size

\begin{tabular}{|c|c|c|c|c|c|}
\hline & $\begin{array}{l}\text { Small-size colleges } \\
\text { ( } \leq 5000 \text { students })\end{array}$ & $\begin{array}{l}\text { Medium-size colleges } \\
\text { (5001-10,000 students) }\end{array}$ & $\begin{array}{l}\text { Large-size colleges } \\
(>10,000 \text { students })\end{array}$ & Total & Test of difference \\
\hline & $\mathrm{N}(\%)$ & $\mathrm{N}(\%)$ & $\mathrm{N}(\%)$ & $\mathrm{N}(\%)$ & \\
\hline Number of colleges & $76(50.7)$ & $37(24.6)$ & $37(24.7)$ & $150(100)$ & \\
\hline $\begin{array}{l}\text { Enrollment (Mean, } \\
\text { Range) }\end{array}$ & $1988(55-4,875)$ & $7245(5,027-9,916)$ & $18,197(10,105-63,778)$ & $7823(55-63,778)$ & \\
\hline Public & $15(19.7)^{\mathrm{a}}$ & $24(64.9)^{\mathrm{b}}$ & $24(64.9)^{\mathrm{b}}$ & $63(42)$ & $\chi^{2}=31.3(P<0.001)$ \\
\hline Fully online & $10(13.2)$ & $3(8.1)$ & $2(5.4)$ & $15(10)$ & $\chi^{2}=2.3(n s)$ \\
\hline State & & & & & $\chi^{2}=13.4(P<0.01)$ \\
\hline New York & $55(72.4)$ & $16(43.2)$ & $26(70.3)$ & $97(64.7)$ & \\
\hline Connecticut & $5(6.6)$ & $9(24.3)$ & $2(5.4)$ & $16(10.7)$ & \\
\hline New Jersey & $16(21.1)$ & $12(32.4)$ & $9(24.3)$ & $37(24.7)$ & \\
\hline $\begin{array}{l}\text { Provided general public } \\
\text { health information on } \\
\text { COVID-19 }\end{array}$ & $72(97.3)$ & $32(88.9)$ & $36(97.3)$ & $140(95.2)$ & $\chi^{2}=4.2(n s)$ \\
\hline $\begin{array}{l}\text { Provided information on } \\
\text { reasons for testing }\end{array}$ & $23(30.3)$ & $10(27)$ & $17(45.9)$ & $50(33.3)$ & $\chi^{2}=3.6(n s)$ \\
\hline $\begin{array}{l}\text { Provided statements on } \\
\text { urgency of testing if } \\
\text { exposed }\end{array}$ & $11(14.5)$ & $4(10.8)$ & $6(16.2)$ & $21(14)$ & $\chi^{2}=0.5(n s)$ \\
\hline $\begin{array}{l}\text { Provided information on } \\
\text { COVID-19 testing on } \\
\text { campus }\end{array}$ & $59(77.6)$ & $23(62.2)$ & $25(67.6)$ & $107(71.3)$ & $\chi^{2}=3.3(n s)$ \\
\hline $\begin{array}{l}\text { Provided information on } \\
\text { COVID-19 testing off } \\
\text { campus }\end{array}$ & $36(47.3)$ & $13(35.1)$ & $20(53.8)$ & $69(46)$ & $\chi^{2}=2.8(n s)$ \\
\hline $\begin{array}{l}\text { Conducted surveillance } \\
\text { testing }(\mathrm{n}=146)\end{array}$ & $19(25.3)$ & $13(37.1)$ & $11(30.6)$ & $43(29.5)$ & $\chi^{2}=1.6(n s)$ \\
\hline $\begin{array}{l}\text { Provided informa- } \\
\text { tion on how to make } \\
\text { an appointment for } \\
\text { COVID-19 testing }\end{array}$ & $10(13.2)^{\mathrm{a}}$ & $10(27)^{\mathrm{a}, \mathrm{b}}$ & $13(36.1)^{\mathrm{b}}$ & $33(22.1)$ & $\chi^{2}=8.1(P<0.05)$ \\
\hline $\begin{array}{l}\text { Provided information } \\
\text { about free testing }\end{array}$ & $38(52.1)^{\mathrm{a}}$ & $23(62.1)^{\mathrm{a}, \mathrm{b}}$ & $28(77.8)^{\mathrm{b}}$ & $89(61)$ & $\chi^{2}=7.0(P<0.05)$ \\
\hline $\begin{array}{l}\text { Observed use of social } \\
\text { media to provide infor- } \\
\text { mation on testing }\end{array}$ & $4(5.3)$ & $1(2.9)$ & 0 & $5(3.4)$ & $\chi^{2}=2.1(n s)$ \\
\hline $\begin{array}{l}\text { Reported testing data to } \\
\text { the campus community }\end{array}$ & $61(80.3)$ & $29(78.4)$ & 34 (91.9) & $124(82.7)$ & $\chi^{2}=3.0(n s)$ \\
\hline $\begin{array}{l}\text { Weekly updates on test- } \\
\text { ing data }(\mathrm{n}=124)\end{array}$ & $20(32.8)$ & $14(48.3)$ & $12(35.3)$ & $46(37.1)$ & $\chi^{2}=2.1(n s)$ \\
\hline $\begin{array}{l}\text { Reported positive cases } \\
\text { on campus }\end{array}$ & $54(71.1)$ & $29(78.4)$ & $33(89.2)$ & $116(77.3)$ & $\chi^{2}=4.7(n s)$ \\
\hline $\begin{array}{l}\text { Average number of posi- } \\
\text { tive cases and range } \\
\text { by Mid-December } \\
\text { (per reporting college, } \\
\mathrm{n}=124 \text { ) }\end{array}$ & $24(0-168)^{\mathrm{a}}$ & $159(2-821)^{\mathrm{b}}$ & $103(0-539)^{\mathrm{b}}$ & $77(0-821)$ & $\begin{array}{c}(\mathrm{H}=20.5, \mathrm{df}=2, \\
P<0.001)\end{array}$ \\
\hline $\begin{array}{l}\text { Average time (in min- } \\
\text { utes) spent to navigate } \\
\text { college website looking } \\
\text { for COVID-info }( \pm S D)\end{array}$ & $13.6(3.2)$ & $14.9(3.1)$ & $14.1(3.1)$ & $14(3.2)$ & $(\mathrm{H}=5.5, \mathrm{df}=2, n s)$ \\
\hline
\end{tabular}

${ }^{\mathrm{a}, \mathrm{b}}$ Each superscript letter indicates readability tests whose means did not differ significantly from each other at the $\alpha=0.05$, following post-hoc test 
2020 semester. Almost two-thirds (64.7\%) of the sampled colleges were located in NY state, while one quarter $(24.7 \%)$ were in NJ, and $10.7 \%$ in CT. NY had a larger proportion of smalland large-sized colleges, while medium-sized colleges were more evenly distributed between three states.

Table 1 also presents the analysis of the COVID-19 testing information provided by colleges on their websites. Chi-square analyses were conducted to explore differences between small, medium and large colleges for each of the content categories. Statistically significant differences were observed in regard to the provision of information on how to make an appointment for COVID-19 testing $\left(\chi^{2}(2)=8.1, P<0.05\right)$, and information on free testing $\left(\chi^{2}(2)=7.0, P<0.05\right)$ with larger institutions more likely to provide this information than smaller institutions. A total of $124(82.7 \%)$ of institutions reported testing data to the campus community, with the majority of providing this data biweekly (62.9\%). Interestingly, among three states, NY has a centralized IHE dashboard of COVID19 cases. Schools in NY were more likely to to report testing data to their community than schools in CT and NJ $\left(\chi^{2}(2)=33.5, P<0.001\right)$. Approximately half $(48.5 \%)$ of $\mathrm{NY}$ schools provided information on the number of COVID-cases directly on their websites, while $47.4 \%$ reported this information primarily through the centralized IHE dashboard. Of 124 institutions reporting testing data to the campus community, 116 recorded at least one positive COVID-19 case among their students or staff. The Kruskal-Wallis test indicated significant differences in the number of reported COVID-19 cases $(P<0.001)$ as related to college size, with the smaller-sized institutions reporting a significantly lower number of cases than medium- $(P<0.001)$ and large-sized $(P=0.003)$ institutions, adjusted for multiple comparisons.

Interestingly, all institutions that offered surveillance testing to their students and staff reported information on the number of positive cases to their community compared to $65 \%$ of those who did not offer surveillance testing $\left(\chi^{2}(2)=12.0, P=0.001\right)$. Institutions offering surveillance testing reported a higher number of COVID-19 cases $(\mathrm{N}=43$, mean $=86)$ than those who did not $(\mathrm{N}=79$, mean $=48$ ). A Mann-Whitney test indicated that this difference was statistically significant $(\mathrm{U}=652.5, \mathrm{z}=-5.61$, $P<0.001)$. Comparing three states, schools in CT $(57.1 \%)$ were more likely to conduct surveillance testing than NY $(25.8 \%)$ and $\mathrm{NJ}(28.6 \%)$ schools $\left(\chi^{2}(2)=5.8, P=0.05\right)$. No statistically significant difference in the time taken to collect information between different college sizes was observed.

\section{Discussion}

With decisions to reopen campuses in the Fall semester of 2020 (90\% of IHEs in our sample opted for some form of inperson learning), IHEs were additionally confronted with the task of controlling infections among students, faculty, and staff. While school administrators relied on rules and guidance from the Centers for Disease Control and Prevention (CDC), state governors and state and local health officials, the lack of consensus on the best practices for reopening campuses, including how to proceed with testing, or provide information on testing to students and staff, represented a significant obstacle to reopening efforts.

The findings from this study reveal that in the absence of regulations and consistent guidance, IHEs information on COVID-19 testing procedures and reporting on COVID-19 cases varied despite the proximal geographic nature of the IHEs. The lack of an agreed upon approach to COVID-19 testing and communication at IHEs has been previously documented [13]. Because asymptomatic and pre-symptomatic carriers may be responsible for half or more of all COVID19 transmission [14], robust and frequent COVID-19 testing is critical for controlling outbreaks on campuses [15-17]. Ideally, campus testing plans would include entrance testing [18], symptomatic testing, testing close contacts of symptomatic individuals, and surveillance testing to identify asymptomatic or pre-symptomatic cases [19]. In our sample, CT colleges were more likely to conduct surveillance testing, which was consistent with the state guidelines. However, given lack of logistical capacity for expanded testing and financial strain faced by many colleges this may have not been feasible for many IHEs, particularly for the smaller ones.

In our sample, 116 institutions (77\%) reported at least one positive COVID-19 case among their students or staff, with the smaller-sized institutions reporting a significantly lower number of cases than medium-, and large-sized institutions. While the typical population of college students is not considered to be in the highest risk category for developing severe illness, increases in COVID-19 cases occurred rapidly in the Fall. A New York Times report identified a dramatic increase in the number of COVID-189 cases. After fall reopening: "more than 26, 000 COVID-19 cases at more than 750 colleges across the nation by August 26, and more than 130,000 cases at 1,300 colleges by September 25" [20]. The increase was particularly dramatic in counties where college students comprised at least $10 \%$ of the county population [21] IHEs do not function in isolation, they are an integral part of communities and the connection between outbreaks on campus and deaths in the community cannot be overlooked [21-23]

Various planning strategies for IHEs also recommended developing information-sharing systems in relation to COVID-19. The CDC recommended that "institutional information systems can be used for day-to-day reporting on number of cases and information, such as absenteeism or changes in student and staff health center traffic to detect and respond to an outbreak" [4]. IHEs were encouraged to 
develop and maintain effective communication with diverse campus constituencies, including students with limited English proficiency and those with disabilities [4] In the NYC metropolitan area, larger institutions were more likely to provide students and staff information on how to make an appointment for COVID-19 testing, including information on free testing. Furthermore, NY schools were more likely to report testing data to their community than schools in CT and NJ. It is important to note that NY state recommendations for IHEs included reporting the cases to the state centralized IHE dashboard.

The lack of consistency on COVID-19 information, including reporting of cases on college campuses, shows there is room for improvement. IHEs should develop comprehensive communication strategies related to COVID-19 testing accessible not only by students, but for community members as well. Specifically, IHEs should aim for transparency in COVID-19 communications as IHEs practices and procedures influence the immediate campus community as well as the community at large. Further, health education related to COVID-19 testing is an essential component in understanding asymptomatic spread and why reducing incidence among college students is important. A goal in providing information on IHEs websites should be to minimize search time. Although we did not measure the location of information within webpages, homepage information listings will minimize search time, average length of time searching for this information was substantial. IHEs should provide easily accessible and comprehensive dashboards. Services are available to aid IHEs in the type of information that should be made available to the public [24]. IHEs should go beyond administrator input in planning campus health communications. Students, faculty, staff as well as stakeholders in the geographic community should also be included [10]. Information must be communicated with attention to varying levels of health literacy among US college students [25] and with the knowledge that students may be exposed to significant misinformation on social media and elsewhere [26].

\section{Limitations}

This study has limitations that warrant mention. As with all cross-sectional studies, the results are not generalizable. By virtue of collecting data at a single point of time, this data does not reflect changes in information over time. The focus of the study was to document what information was identified on IHEs websites, but it is possible that information was present in some capacity, was delivered in an alternative way, or was encrypted, but was not readily identified using the methods deployed. Further, the sample size was relatively small, representing a fixed geographic area. While this area is highly populated and was a pandemic epicenter at the beginning of the pandemic, further study with larger samples is justified.

Despite these limitations, this research fills a gap in literature and can serve as a springboard for further inquiry. Inconsistent and inadequate delivery of information related to pandemic by IHEs, particularly when they are geographically close, may further contribute to the lack of awareness and confusion, as well as the inability to make informed health decisions, including decisions on when and where to get tested. IHEs websites are an obvious place to house and update information related to COVID-19. Doing so in a consistent, timely, transparent, and comprehensive way may significantly contribute in efforts to curb community transmission.

Author Contributions CB and MS conceptualized the study. NQ collected the data. AK conducted the data analysis. All authors contributed to the manuscript production.

Funding None.

\section{Compliance with Ethical Standards}

Competing interests None of the authors report a conflict of interest.

Ethical approval The William Paterson University Institutional Review Board does not review studies that do not involve human subjects.

\section{References}

1. NYC Planning. (n.d.). New York City A City of Neighborhoods. Retrieved January 20, 2021, from https://www1.nyc.gov/site/ planning/data-maps/city-neighborhoods.page

2. Marsicano, C. R., Felten, K. M., Toldeo, L., \& Buitendorp, M. (2020). Tracking Campus Responses to the COVID-19 Pandemic. https://doi.org/https://doi.org/10.33774/APSA-2020-3WVRL

3. Higher Education Subcommittee. (2020). Report of the Higher Education Subcommittee Reopen Connecticut. Retrieved from https://portal.ct.gov/-/media/Office-of-the-Governor/News/20200 506-Recommendations-to-Governor-Lamont-for-a-phased-reope ning-of-colleges-and-universities.pdf.

4. CDC. (2020). Considerations for Institutions of Higher Education. Retrieved January 20, 2021, from https://www.cdc.gov/coronaviru s/2019-ncov/community/colleges-universities/considerations. html.

5. Bazelon, E. (2020). What Will College Be Like in the Fall?The New York Times. New York Times Magazine. New York. Retrieved from https://www.nytimes.com/2020/06/03/magazine/ covid-college-fall.html.

6. Office of the Secretary of Higher Education. (2020). Office of the Secretary of Higher Education (OSHE) Restart Standards for all New Jersey Institutions of Higher Education. Retrieved from https ://www.state.nj.us/highereducation/documents/pdf/index/OSHEr estart.pdf 
7. Reopening New York. (n.d.). Reopening New York Higher Education Guidelines. Retrieved from https://www.governor.ny.gov/ sites/governor.ny.gov/files/atoms/files/Higher_Education_Summa ry_Guidelines.pdf.

8. Bradley, E. H., An, M. W., \& Fox, E. (2020). Reopening colleges during the Coronavirus Disease 2019 (COVID-19) pandemic-one size does not fit all. JAMA Network Open. https://doi.org/10.1001/ jamanetworkopen.2020.17838.

9. Hartocollis, A., \& Hubler, S. (2020). Covid tests and quarantines: Colleges brace for an uncertain fall. New York Times. Retrieved from https://www.nytimes.com/2020/08/02/us/covid-collegereopening.html.

10. Galván, A., Cauffman, E., \& Brossard, D. (2020). Encouraging protective COVID-19 behaviors among college students. Encouraging protective COVID-19 behaviors among college students. National Academies Press. https://doi.org/https://doi.org/10.17226 126004.

11. National Center for Education Statistics. (n.d.). College Navigator . Retrieved January 20, 2021, from https://nces.ed.gov/collegenav igator/.

12. IBM Corp. (2019). IBM SPSS Statistics for Windows, Version 26.0.

13. Booeshaghi, A. S., Tan, F., Renton, B., Berger, Z., \& Pachter, L. (2020). Markedly heterogeneous COVID-19 testing plans among US colleges and universities. medRxiv. Retrieved from https://www.medrxiv.org/content/https://doi. org/10.1101/2020.08.09.20171223v1.

14. Johansson, M. A., Quandelacy, T. M., Kada, S., Pragati, ;, Prasad, V., Steele, M., ... Butler, J. C. (2021). SARS-CoV-2 transmission from people without COVID-19 symptoms. JAMA Network Open, 4(1), e2035057-undefined.

15. Paltiel, A. D., Zheng, A., \& Walensky, R. P. (2020). Assessment of SARS-CoV-2 screening strategies to permit the safe reopening of college campuses in the United States. JAMA Network Open, 3(7), e2016818. https://doi.org/10.1001/jamanetworkopen.2020.16818

16. Bahl, R., Eikmeier, N., Fraser, A., Junge, M., Keesing, F., Nakahata, K., \& Wang, L. Z. (2020). Modeling COVID-19 spread in small colleges. arXiv. Retrieved from https://arxiv.org/ abs/2008.09597.

17. Lopman, B., Liu, C. Y., le Guillou, A., Handel, A., Lash, T. L., Isakov, A. P., \& Jenness, S. M. (2020). A model of COVID-19 transmission and control on university campuses. MedRxiv. https ://doi.org/10.1101/2020.06.23.20138677.
18. Rennert, L., Kalbaugh, C. A., Shi, L., \& Mcmahan, C. (2020). Modelling the impact of presemester testing on COVID-19 outbreaks in university campuses. British Medical Journal Open. https://doi.org/10.1136/bmjopen-2020-042578.

19. Walke, H. T., Honein, M. A., \& Redfield, R. R. (2020). Preventing and responding to COVID-19 on college campuses. JAMA. https ://doi.org/10.1001/jama.2020.20027.

20. New York Times. (2020). Tracking the Coronavirus at U.S. Colleges and Universities. New York Times. Retrieved January 20, 2021, from https://www.nytimes.com/interactive/2020/us/covid -college-cases-tracker.html.

21. Ivory, D., Gebeloff, R., \& Mervosh, S. (2020). Young People Have Less Covid-19 Risk, but in College Towns, Deaths Rose Fast. New York Times. Retrieved from https://www.nytimes.com/2020/12/12/ us/covid-colleges-nursing-homes.html.

22. Watson, S., Hubler, S., Ivory, D., \& Geboloff, R. (202). A New Front in Coronavirus Pandemic: College Towns. New York Times. Retrieved from https://www.nytimes.com/2020/09/06/us/collegescoronavirus-students.html.

23. Richmond, C. S., Sabin, A. P., Jobe, D. A., Lovrich, S. D., \& Kenny, P. A. (2020). SARS-CoV-2 sequencing reveals rapid transmission from college student clusters resulting in morbidity and deaths in vulnerable populations. medRxiv. https://doi. org/10.1101/2020.10.12.20210294v1.

24. We Rate Covid Dashboards. (n.d.). Retrieved January 20, 2021, from https://www.ratecoviddashboard.com/.

25. Chesser, A., Drassen Ham, A., \& Keene Woods, N. (2020). Assessment of COVID-19 knowledge among university students: implications for future risk communication strategies. Health Education and Behavior, 47(4), 540-543. https://doi. org/10.1177/1090198120931420.

26. Mheidly, N., \& Fares, J. (2020). Leveraging media and health communication strategies to overcome the COVID-19 infodemic. Journal of Public Health Policy, 41, 410-420. https://doi. org/10.1057/s41271-020-00247-w.

Publisher's Note Springer Nature remains neutral with regard to jurisdictional claims in published maps and institutional affiliations. 